\title{
Growth inhibition of human hepatocellular carcinoma cells by antagonism of the $\beta_{2}$ adrenergic receptor
}

\author{
DONGMEI DANG ${ }^{1}$, JING ZHANG ${ }^{2}$ and JIANJUN YANG ${ }^{3}$ \\ Departments of ${ }^{1}$ Pathogen Biology and ${ }^{2}$ Genetics, Medical College of Yan'an University; \\ ${ }^{3}$ Department of Interventional Radiology, Affiliated Hospital of Yan'an University, Yan'an, Shaanxi 716000, P.R. China
}

Received February 27, 2016; Accepted February 1, 2017

DOI: $10.3892 / \mathrm{ol} .2018 .8847$

\begin{abstract}
Previous studies have shown that the activation of the $\beta_{2}$ adrenergic receptor (ADRB2) can stimulate several signaling pathways that promote tumor growth and metastasis. $\beta$-adrenergic antagonism may have a beneficial role in cancer treatment; however, little is known about the effect of ADRB2 inhibition on the growth of human hepatocellular carcinoma (HCC) cells. The present study revealed that ADRB2 was highly expressed in HCC cell lines compared with that in a normal liver cell line. Treatment with the ADRB2 antagonists ICI118,551 and metoprolol significantly inhibited the growth of human HCC cells. Annexin V/propidium iodide apoptosis and Hoechst staining assays revealed that treatment with ADRB2 antagonists induced apoptosis in HCC cells. Additionally, cell cycle analysis using propidium iodide staining demonstrated that growth suppression was associated with $\mathrm{G}_{2} / \mathrm{M}$ phase cell cycle arrest by ADRB2 antagonism in HCC cells. Treatment with the ADRB2 antagonists suppressed HCC growth, possibly through inhibiting expression of B-cell lymphoma-2 (Bcl-2) and upregulating that of caspase-9 and Bcl-2-associated $\mathrm{X}$, as well as downregulating the expression levels of the $G_{2} / M$ phase-associated proteins cyclin $B 1$ and cyclin-dependent kinase 1 . Therefore, the observations of the present study indicate that ADRB2 blockade inhibited HCC growth, potentially mediated by inducing apoptosis and $\mathrm{G}_{2} / \mathrm{M}$ phase cell cycle arrest. ADRB2 antagonists may therefore be a promising therapeutic strategy for HCC.
\end{abstract}

\section{Introduction}

Hepatocellular carcinoma (HCC) is the fifth-most common malignancy worldwide, and the fastest-increasing cause of cancer-associated mortality in the USA $(1,2)$. Despite substantial improvements to the therapeutic strategies

Correspondence to: Dr Jianjun Yang, Department of Interventional Radiology, Affiliated Hospital of Yan'an University, 43 North Main Street, Baota, Yan'an, Shaanxi 716000, P.R. China

E-mail: yangjianjun1975@yeah.net

Key words: $\beta_{2}$ adrenergic receptor, hepatocellular carcinoma, apoptosis, $\mathrm{G}_{2} / \mathrm{M}$ phase arrest used to treat $\mathrm{HCC}$, the overall prognosis of patients with HCC remains poor, with a 5-year survival rate of $12 \%$ (3). Therefore, the identification of novel molecular targets for early diagnosis and effective treatment of HCC is urgently required.

Evidence supports a hypothesis that chronic stress can affect tumor growth and progression (4); activation of the adrenergic system increases tumor growth and has been shown to mediate stress-induced augmentation of tumor progression (4,5). The $\beta_{2}$ adrenergic receptor (ADRB2) is a member of the superfamily of adrenergic G-protein-coupled receptors (GPCRs), and is widely expressed in the majority of cell types (6); it is the primary target of the catecholamine epinephrine during the stress response (7). Previous studies have demonstrated that the activation of ADRB2 can stimulate several signaling pathways, including the Ras-mediated Raf proto-oncogene serine/threonine-protein kinase (Raf)/dual specificity mitogen-activated protein kinase kinase (MEK)/extracellular signal-regulated kinase (ERK), phosphoinositide 3-kinase $(\mathrm{PI} 3 \mathrm{~K}) / \mathrm{RAC}$ serine/threonine-protein kinase (Akt) and cAMP/protein kinase A/mitogen-activated protein kinase pathways that promote cellular proliferation and invasion, and suppress apoptosis in cancer cells, which can enhance tumor growth and facilitate metastasis (8). $\beta$-adrenergic blockers have been used clinically to reduce the rates of progression of several types of solid tumor (9). The use of $\beta$-adrenergic blockers resulted in a $57 \%$ reduction in the risk of metastasis and a $71 \%$ reduction in the 10 -year mortality rate in patients with breast cancer $(10,11)$. In addition, ICI118551, an ADRB2 blocker, significantly synergized with the anti-proliferative and pro-apoptotic effects of gemcitabine to inhibit the proliferation of pancreatic cancer cells (12). These results indicate that ADRB2 blockade may serve a role in cancer treatment.

On the basis of previous results concerning the association between tumor growth and ADRB2, the present study set out to examine whether ADBR2 antagonism could suppress HCC growth. The present study tested the inhibitory effect of ADRB2 blockade on the growth of human HCC cells and examined the potential molecular mechanism by which ADRB2 blockade causes this growth inhibition.

\section{Materials and methods}

Cell culture and reagents. The human HCC SMMC-7721, Huh7 and Hep3B cell lines, and the normal liver L02 cell 
line were purchased from American Type Culture Collection (Manassas, VA, USA) and were cultured in Dulbecco's modified Eagle's medium (Gibco; Thermo Fisher Scientific, Inc., Waltham, MA, USA) supplemented with $10 \%$ fetal bovine serum (Gibco; Thermo Fisher Scientific, Inc.) and maintained at $37^{\circ} \mathrm{C}$ in a humidified incubator containing $5 \% \mathrm{CO}_{2}$. The $\beta$-adrenergic antagonists, metoprolol and ICI118,551 were purchased from Sigma-Aldrich; Merck KGaA (Darmstadt, Germany).

$R N A$ extraction and reverse transcription-quantitative polymerase chain reaction $(R T-q P C R)$. Total RNA was extracted from cells using TRIzol (Invitrogen; Thermo Fisher Scientific, Inc.) according to the manufacturer's protocol. The total RNA concentration was assessed by measuring absorbance at $260 \mathrm{~nm}$ using a NanoDrop spectrophotometer (ND-1,000; Thermo Fisher Scientific, Inc.). Next, $2 \mu \mathrm{g}$ of total RNA was reverse-transcribed to cDNA using the PrimeScript RT Reagent kit (Takara Bio, Inc., Tokyo, Japan). Gene-specific amplification was performed using ABI 7,500 fast real-time PCR system (Applied Biosystems; Thermo Fisher Scientific, Inc.) and SYBR Green PCR Master Mix (Applied Biosystems; Thermo Fisher Scientific, Inc.) according to the manufacturer's protocol. Thermocycling conditions for PCR were as follows: First step at $95^{\circ} \mathrm{C}$ for $10 \mathrm{~min}$ followed by 40 cycles at $95^{\circ} \mathrm{C}$ for $15 \mathrm{sec}$ and $60^{\circ} \mathrm{C}$ for $1 \mathrm{~min}$. For the analysis of the melting curve at the end of $\mathrm{PCR}$, the reaction mixture was heated to $95^{\circ} \mathrm{C}$, followed by complete annealing at $60^{\circ} \mathrm{C}$ and then followed by a gradual increase in temperature up to $95^{\circ} \mathrm{C}$. The following gene-specific primers were used in the present study: ADRB2 forward, 5'-GCCTGTGCTGATCTGGTC AT-3' and reverse, 5'-AATGGAAGTCCAAAACTCGCA-3'; $\beta$-actin forward, 5'-GTGGACATCCGCAAAGAC-3' and reverse, 5'-AAAGGGTGTAACGCAACTA-3'. The relative expression level of ADRB2 was normalized to the expression of the housekeeping gene $\beta$-actin using the comparative threshold cycle $\left(2^{-\Delta \Delta \mathrm{Cq}}\right)$ method (13). Each sample was analyzed in triplicate and the mean expression level was calculated.

Cell viability assay. Cells were harvested and seeded into 96-well plates at a density of $2 \times 10^{3}$ cells per well and cultured in an environment with $5 \% \mathrm{CO}_{2}$ at $37^{\circ} \mathrm{C}$. During the experiments, cells were incubated with metoprolol $(0,5,10,20$, $50,100$ and $200 \mu \mathrm{M})$ or ICI118,551 $(0,5,10,20,50,100$ and $200 \mu \mathrm{M})$; Dimethyl sulfoxide $(0.05 \%)$ was used as vehicle control. Next, $10 \mu \mathrm{l}$ Cell Counting kit-8 solution (Dojindo Molecular Technologies, Inc., Kumamoto, Japan) was added into the culture medium in each well at the indicated time $(12,24,48,72$ and $96 \mathrm{~h})$. After a 1 -h incubation at $37^{\circ} \mathrm{C}$, optical density values were obtained using a microplate reader at a 450 -nm wavelength. The experiment at each time point was repeated in triplicate and the experiment was independently performed three times.

Cell apoptosis assay. Cell apoptosis was evaluated by flow cytometry using an Annexin V-Fluorescein Isothiocyanate (FITC) Apoptosis Detection kit (Nanjing KeyGen Biotech Co., Ltd., Nanjing, China). Briefly, $1 \times 10^{5}$ cells were treated with metoprolol $(50 \mu \mathrm{M})$ or ICI118,551 $(50 \mu \mathrm{M})$ for $48 \mathrm{~h}$. Next, cells were harvested, washed, resuspended in the

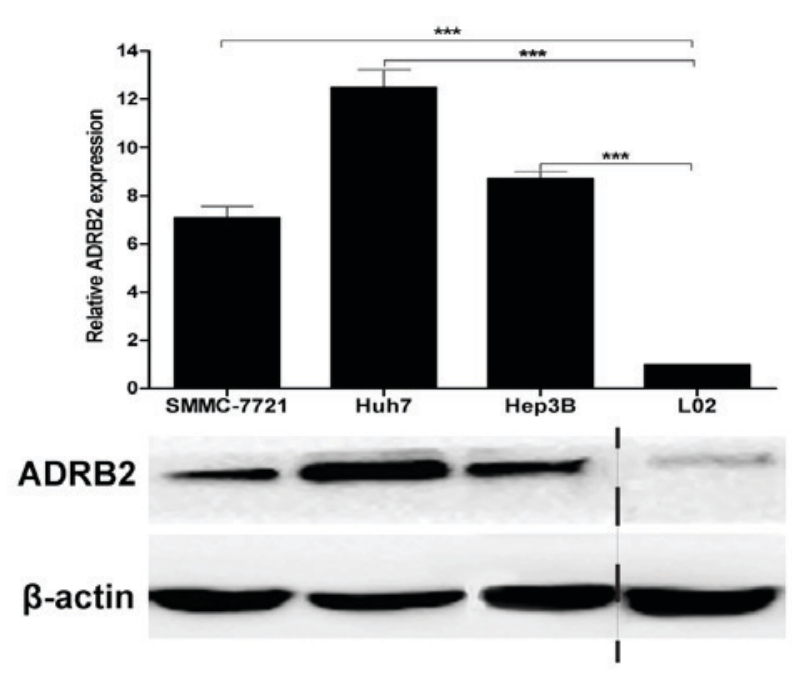

Figure 1. Expression levels of ADRB2 in human hepatocellular carcinoma cells. Reverse transcription-quantitative polymerase chain reaction (above) and western blotting analysis (below) revealing the expression of ADRB2 in HCC SMMC-7721, Huh7 and Hep3B cell lines and the normal liver L02 cell line. Data shown are mean \pm standard deviation from three independent experiments. ${ }^{* * *} \mathrm{P}<0.001$. ADBR2, $\beta_{2}$ adrenergic receptor. Note: The division between Hep3B and L02 lane in the western blot image corresponds to supplementary data that were not required, and consequently removed.

binding buffer. A volume of $5 \mu \mathrm{l}$ Annexin V-FITC and $5 \mu \mathrm{l}$ propidium iodide (PI) was added and mixed gently, and the cells were stained in the dark for $10 \mathrm{~min}$ at room temperature. The cells were analyzed immediately by flow cytometry (BD FACSCalibur; BD Biosciences, San Diego, CA, USA) and analyzed using FlowJo software (version 7.6; FlowJo, LLC, Ashland, OR, USA). The experiment was repeated three times.

Hoechst 33342 staining. A total of $2 \times 10^{5}$ Cells were exposed to metoprolol $(50 \mu \mathrm{M})$, or ICI118,551 $(50 \mu \mathrm{M})$ for $48 \mathrm{~h}$. Cells were fixed in $4 \%$ paraformaldehyde for $10 \mathrm{~min}$ at room temperature and permeabilized with $0.1 \%$ Triton X-100 for $5 \mathrm{~min}$ at room temperature, then stained with $10 \mu 1$ Hoechst 33342 (Sigma-Aldrich; Merck KGaA) for $10 \mathrm{~min}$ at room temperature. Next, cells were viewed with a confocal microscope (Olympus Corporation, Tokyo, Japan). Quantitative analysis was performed by counting the blue fluorescent (apoptosis-positive) cells from three independent fields at magnification, $x 400$. Values were expressed as the percentage of apoptotic cells relative to the total number of cells per field.

Cell cycle analysis. Cells were exposed to metoprolol $(50 \mu \mathrm{M})$, or ICI118,551 $(50 \mu \mathrm{M})$ for $48 \mathrm{~h}$. Cells were harvested and fixed in $70 \%$ ethanol and stored at $-20^{\circ} \mathrm{C}$ for $6 \mathrm{~h}$, then washed twice with ice-cold PBS and incubated with RNase A and PI (both Sigma-Aldrich; Merck KGaA) for $30 \mathrm{~min}$ in the dark at room temperature. Cell cycle assay was performed using a flow cytometer (BD FACSCalibur; BD Biosciences). Cell cycle phase analysis was performed using the Modifit cell cycle analysis software (version 2.0; BD Biosciences). The experiment was independently performed for three times.

Western blot analysis. Cells were exposed to metoprolol $(50 \mu \mathrm{M})$, or ICI118,551 $(50 \mu \mathrm{M})$ for $48 \mathrm{~h}$. Following this, total proteins from treated cells was lysed in Radioimmunoprecipitation Assay 

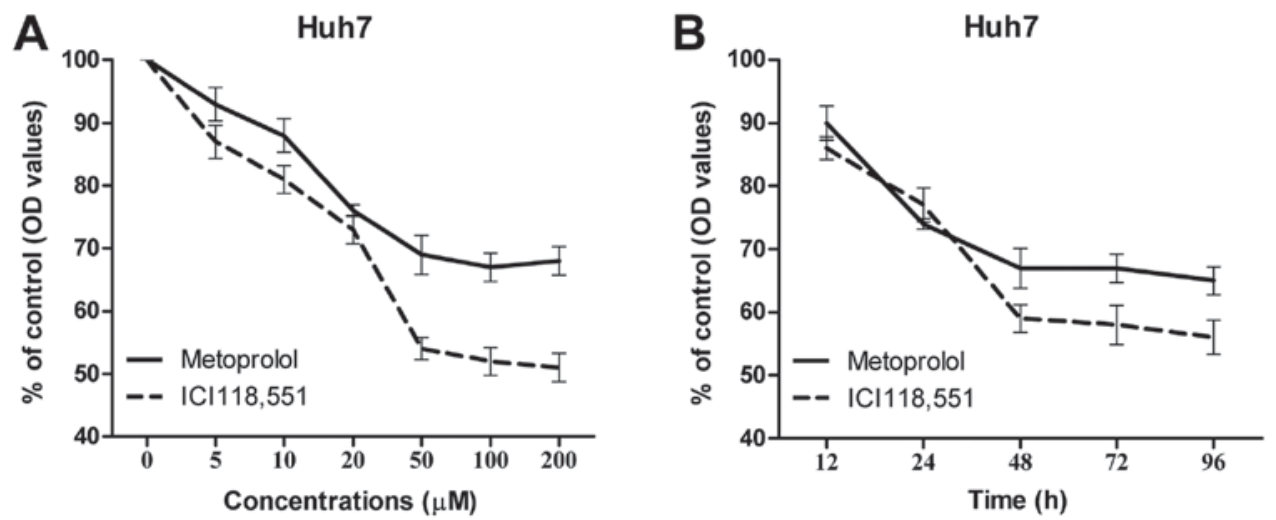

Figure 2. Antagonism of the $\beta_{2}$ adrenergic receptor inhibits proliferation in HCC cells. (A) Huh7 cells were exposed to various concentrations of $\beta$-adrenergic antagonists ICI118,551 and metoprolol for $48 \mathrm{~h}$, and the cell growth was measured using a CCK-8 assay. (B) Huh7 cells were exposed to 50 $\mu$ M ICI118,551 or metoprolol for the indicated times and the cell growth was measured using a CCK- 8 assay. Data shown are mean \pm standard deviation from three independent experiments. OD, optical density; CCK-8, Cell Counting kit-8.

buffer (Beyotime Institute of Biotechnology, Shanghai, China). The protein concentration was quantified using a Bicinchoninic Acid Assay kit (Beyotime Institute of Biotechnology) according to the manufacturer's protocol. A total of $30 \mu \mathrm{g}$ total protein were separated by $10 \%$ SDS-PAGE and the protein was transferred onto polyvinylidene fluoride membranes. The membrane was then blocked with TBST (10 mM Tris- $\mathrm{HCl}$, $\mathrm{pH} 7.4,150 \mathrm{mM} \mathrm{NaCl}, 0.1 \%$ Tween-20) containing 5\% w/v non-fat dry milk for $2 \mathrm{~h}$ at room temperature and then incubated with the primary antibodies to ADRB2 (1:1,000; ab182136), caspase-9 (1:1,000; ab32539), B-cell lymphoma-2 (Bcl-2; 1:1,000; ab32124), Bcl-2 associated X (Bax; 1:1,000; ab32503), cyclin B1, cyclin-dependent kinase 1 (CDK1; 1:10,000; ab133327) or $\beta$-actin $(1: 3,000$; ab8226; all from Abcam, Cambridge, MA, USA) at $4^{\circ} \mathrm{C}$ overnight. The membrane was washed three times and was then incubated with the horseradish peroxidase-conjugated goat anti-rabbit secondary antibody $(1: 5,000 ; \mathrm{ab} 7090)$ or goat anti-mouse secondary antibody (1:5,000; ab97040; all from Abcam, Cambridge, MA, USA) for $2 \mathrm{~h}$ at room temperature. The bands were visualized using the electrogenerated chemiluminescence detection system (EMD Millipore, Billerica, MA, USA).

Statistical analysis. Data are represented as the mean \pm standard deviation. Data were analyzed using GraphPad Prism 5 software for Windows (GraphPad Software, Inc., La Jolla, CA, USA). Differences between groups were assessed using one-way analysis of variance with post hoc Dunnet's test. $\mathrm{P}<0.05$ was considered to indicate a statistically significant difference.

\section{Results}

Expression of ADRB2 in HCC cell lines. A previous study has shown that ADRB2 is in general expressed at higher levels in HCC tissues than in benign nontumor liver tissues (14). To assess basal ADRB2 levels in HCC cell lines, ADRB2 expression was examined in the HCC SMMC-7721, Huh7 and Hep3B cell lines and the normal liver L02 cell line by RT-qPCR and western blot analysis. ADRB2 was highly expressed in all three HCC cell lines assessed compared with normal liver cell line L02 (Fig. 1).
Inhibition of ADBR2 inhibits cell growth in HCC cells. Next, the growth inhibitory effects of ADBR2 inhibition on the Huh7 HCC cell line were assessed. Various concentrations of the $\beta$-adrenergic antagonists metoprolol and ICI118,551 between 5 and $200 \mu \mathrm{M}(5,10,20,50,100$ and $200 \mu \mathrm{M})$ were used to treat Huh7 cells for $48 \mathrm{~h}$, cell growth was assessed by CCK-8 assay. As depicted in Fig. $2 \mathrm{~A}$, treatment with the $\beta$-adrenergic antagonists significantly decreased cell growth compared with the control group with dose dependent effects; the optimal concentration was $50 \mu \mathrm{M}$ for the two $\beta$-adrenergic antagonists used. A time-course cell growth assay was also performed to examine the optimal timing, the results revealed that metoprolol and ICI118,551 (each at $50 \mu \mathrm{M}$ ) reached the maximum efficacy at 48 h, with 70 and $60 \%$ inhibition of viability; no further decrease in cell viability at later time points (Fig. 2B).

Inhibition of ADBR2 induces cell apoptosis in HCC cells. To determine whether the effects of ADBR2 inhibition were associated with induction of apoptosis or reduction of cell proliferation in HCC cells, an Annexin V/PI apoptosis assay and Hoechst staining were performed, respectively. To examine the effect of the antagonists on HCC cell apoptosis, $50 \mu \mathrm{M}$ metoprolol or ICI118,551. As shown in Fig. 3A and B, the percentage of apoptotic cells significantly increased when cells were exposed to $\beta$-adrenergic antagonists for 48 h. Additionally, Hoechst staining revealed that the cells exhibited the characteristic appearance of apoptotic cells following treatment with the two $\beta$-adrenergic antagonists for $48 \mathrm{~h}$ (Fig. 3C). Treatment with the $\beta$-adrenergic antagonists resulted in a significant increase in the number of apoptotic cells compared with the basal apoptotic level in the untreated controls (Fig. 3C). The percentage of apoptotic cells in the $\beta$-adrenergic antagonists-treated HCC cells were significantly different from the untreated control cells (Fig. 3D).

Inhibition of $A D B R 2$ induces $G_{2} / M$ phase cell cycle arrest in HCC cells. To examine the inhibitory effects of ADBR2 antagonsim on HCC cell growth, the cell cycle distribution was examined by flow cytometry using the PI staining method. As depicted in Fig. 4A and B, treatment of Huh7 cells with the $\beta$-adrenergic antagonists for $48 \mathrm{~h}$ caused a significant increase 
A

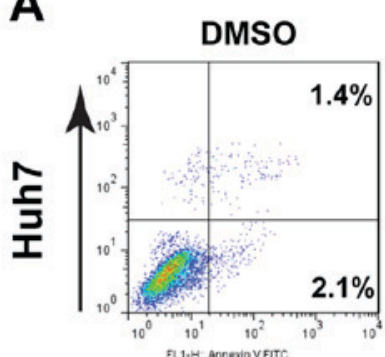

Annexin V
ICI118,551

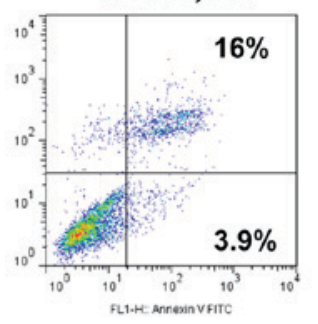

Metoprolol

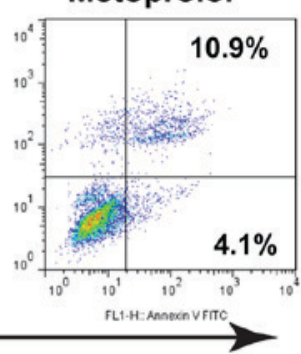

B

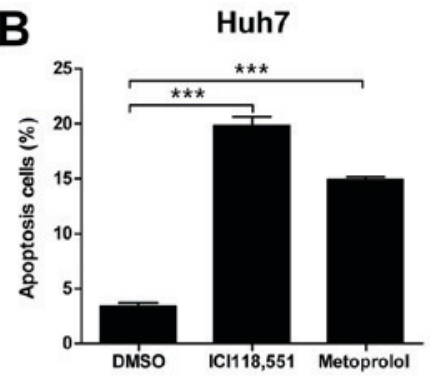

C

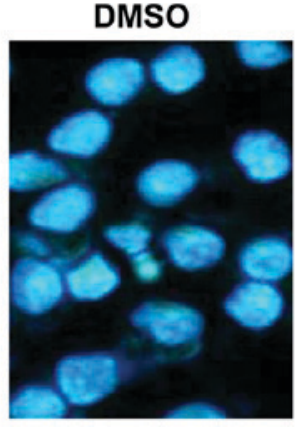

ICI118,551

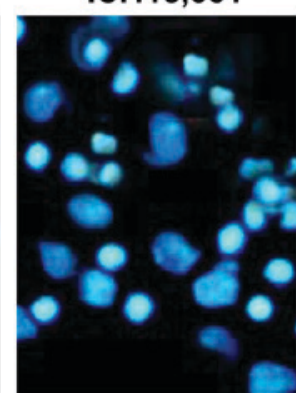

Metoprolol

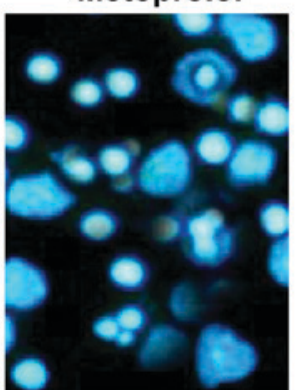

D

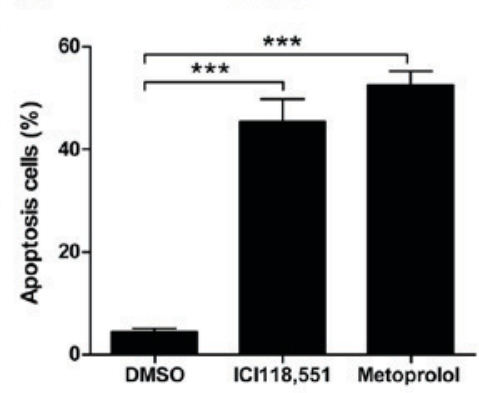

Figure 3. Antagonism of the $\beta_{2}$ adrenergic receptor induces cell apoptosis in hepatocellular carcinoma cells. Huh7 cells were exposed to $50 \mu \mathrm{M} \beta$-adrenergic antagonists ICI118,551 and metoprolol for $48 \mathrm{~h}$. (A) Apoptosis in Huh-7 cells was examined using Annexin V/propidium iodide staining by flow cytometry, then (B) quantified. (C and D) Hoechst 33258 staining was used to observe (C) the morphological changes of cell apoptosis (magnification, $\mathrm{x} 200)$ and (D) the apoptotic cells were quantified. Data shown are mean \pm standard deviation from three independent experiments. ${ }^{* * *} \mathrm{P}<0.001$. DMSO, dimethyl sulfoxide.

in the proportion of cells in $\mathrm{G}_{2} / \mathrm{M}$ phase, when compared with the untreated control cells. Specifically, the proportion of Huh7 cells in $\mathrm{G}_{2} / \mathrm{M}$ phase increased from 24.1 to $65.4 \%$ following ICI118,551 treatment, and to $68.1 \%$ for metoprolol treatment. These results indicate that antagonism of ADBR2 leads to arrest in the $\mathrm{G}_{2} / \mathrm{M}$ phase of the cell cycle in $\mathrm{HCC}$ cells. Taken together, these results indicate that inhibition of ADBR2 induced cell apoptosis and cell cycle arrest in HCC cells, which led to cell growth inhibition.

Inhibition of ADBR2 downregulates the expression of $\mathrm{Bcl}-2$ and cyclin Bl in HCC cells. To determine the molecular mechanisms that were involved in apoptosis and $\mathrm{G}_{2} / \mathrm{M}$ phase cell cycle arrest, several cell apoptosis and cell cycle relevant proteins were screened for changes in expression level in Huh7 cells following treatment with ICI118,551 $(50 \mu \mathrm{M})$ or metoprolol $(50 \mu \mathrm{M})$. As depicted in Fig. 5, the expression of Bcl-2 were decreased following treatment with either antagonist, whereas the cleavage of caspase-9 and Bax increased, compared with the control cells. In addition, expression of the $\mathrm{G}_{2} / \mathrm{M}$ phase proteins cyclin $\mathrm{B} 1$ and CDK1 were downregulated in Huh7 cells treated with $\beta$-adrenergic antagonists.

\section{Discussion}

ADRB2 has been studied for more than four decades, it belongs to the GPCR superfamily, and can regulate cancer development (15). Recently, emerging evidence has demonstrated the association between $\beta$-adrenergic antagonism and cancer. $\beta$-adrenergic antagonists also exert antitumor effects via non-genomic mechanisms, including matrix metalloproteinase, mitogen-activated protein kinase pathways, prostaglandins, cyclooxygenase-2, oxidative stress and nitric oxide synthase; thus, treatment with these antagonists may exert a beneficial clinical effect in patients with cancer (8). The present study demonstrated that ADRB2 was highly expressed in human HCC cells; ADBR2 antagonism attenuated HCC cell growth by inducing cell apoptosis and $\mathrm{G}_{2} / \mathrm{M}$ phase cell cycle arrest. The results of the present study also indicated that this mechanism may involve elevated levels of caspase- 9 and Bax expression and downregulation of Bcl-2, cyclin B1 and CDK1. The results of the current study indicate that ADRB2 antagonists may therefore represent a promising therapeutic strategy for HCC.

ADRB2 is primarily distributed at the cell membrane, although its expression in different cells and tissues varies (16). ADRB2 is expressed in pancreatic cancer BxPC-3, MIA PaCa-2 and Panc-1 cell lines (17,18); breast cancer IBH-4, IBH-6 and MDA-MB-231 cell lines (19); and human astrocytoma U118 and $1321 \mathrm{~N} 1$ cell lines (20). The present study revealed the presence of high ADRB2 expression in HCC SMMC-7721, Huh7 and Hep3B cell lines, but no expression in the normal liver L02 cell line. Kassahun et al (14) reported that the ADRB2 density was higher in HCC liver membranes than the density in the nonadjacent nontumor liver membranes. In addition, ADRB2 protein expression was increased 1.5-fold when compared with nonmalignant controls (14), which was consistent with the results of the present study in HCC cell lines, indicating that ADRB2 was upregulated in human HCC. However, Kassahun et al (14) did not investigate the mechanisms responsible for this change in the growth of $\mathrm{HCC}$ and the nature of this alteration further. The changes in ADRB2 expression observed in HCC tissues and cell lines in 
A

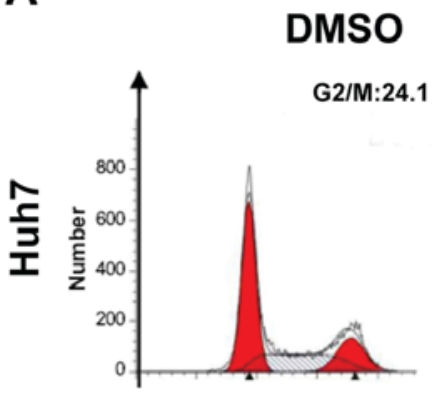

ICI118,551

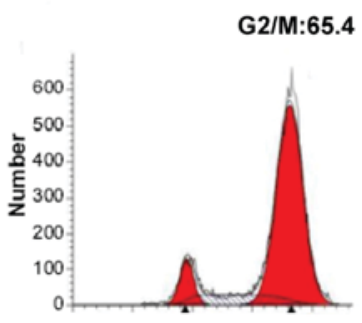

Metoprolol

G2/M:68.1

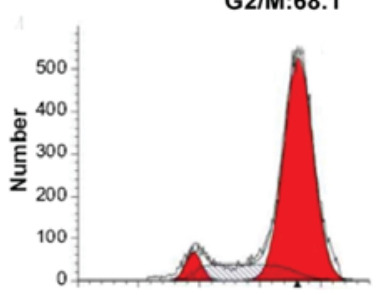

B

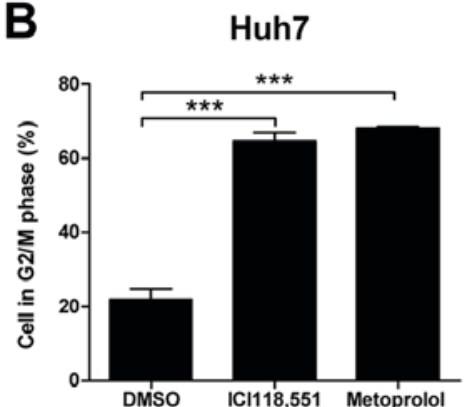

Figure 4. Antagonism of the $\beta_{2}$ adrenergic receptor induces $\mathrm{G}_{2} / \mathrm{M}$ phase cell cycle arrest in hepatocellular carcinoma cells. Huh7 cells were exposed to $50 \mu \mathrm{M}$ $\beta$-adrenergic antagonists ICI118,551 and metoprolol for $48 \mathrm{~h}$, the cell cycle distribution was analyzed by flow cytometry. (A) Representative cell cycle histograms were shown. (B) The statistical data was analysed. Data shown are mean \pm standard deviation from three independent experiments. ${ }^{\text {**** }} \mathrm{P}<0.001$. DMSO, dimethyl sulfoxide.

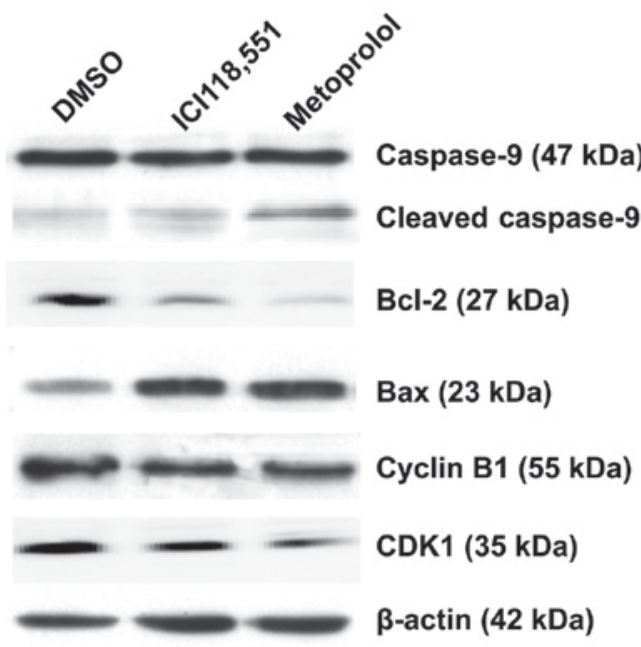

Figure 5. Antagonism of the $\beta_{2}$ adrenergic receptor downregulates the expression of Bcl-2 and cyclin B1 in hepatocellular carcinoma cells. Huh7 cells were exposed to $50 \mu \mathrm{M} \beta$-adrenergic antagonists ICI118,551 and metoprolol for $48 \mathrm{~h}$, the expression of the respective proteins in the whole cell lysates was examined by western blotting. Bcl-2, B-cell lymphoma-2; Bax, Bcl-2-associated X; CDK1, cyclin-dependent kinase 1; DMSO, dimethyl sulfoxide.

the current study may reflect cellular defects following tumor growth and progression.

The association between $\beta$-adrenergic antagonism and cancer has been well established. Zhang et al (21) reported that ADRB2 inhibition induces $\mathrm{G}_{1} / \mathrm{S}$ phase arrest and apoptosis in pancreatic cancer cells via the Ras/Akt/nuclear factor $-\kappa \mathrm{B}(\mathrm{NF}-\kappa \mathrm{B})$ pathway. They also observed that ADRB2 antagonists suppress pancreatic cancer cell invasion by inhibiting cAMP response element binding protein, $\mathrm{NF}-\kappa \mathrm{B}$ and activator protein-1 (18). In addition, Liao et al (22) reported that the $\beta$-adrenoreceptor antagonist propranolol enhanced the sensitivity of gastric cancer cells to radiation by inhibiting $\beta$-adrenergic receptors and the downstream $\mathrm{NF}-\kappa \mathrm{B} /$ vascular endothelial growth factor/epidermal growth factor receptor/cyclooxygenase-2 pathway. In the present study, ADRB2 antagonism induced $\mathrm{G}_{2} / \mathrm{M}$ phase arrest and apoptosis in HCC cells via inhibiting Bcl-2, cyclin B1 and CDK1. However, Pérez Piñero et al (19) reported that the $\beta$-adrenoreceptor agonists isoprenaline and salbutamol inhibited breast cancer cell proliferation and tumor growth, an effect that could be reversed by treatment with the $\beta$-adrenoreceptor antagonist propranolol, indicating that the role of ADRB2 signaling is complex and the actions of the agonists or antagonists can elicit a wide range of effects. ADRB2 agonists can stimulate activation of Src tyrosine kinase and Ras, and activation of the Raf/MEK/ERK and PI3 K/Akt pathways, promoting tumor growth and disease progression $(17,23)$. Taken together, alternation of ADRB2 signaling, by treatment with either agonists or antagonists, could markedly change the cellular processes, potentially leading to tumor growth inhibition.

In summary, the results of the present study demonstrated the growth inhibition effects of ADRB2 antagonism in HCC cells. This inhibitory role was likely mediated by induction of apoptosis and $\mathrm{G}_{2} / \mathrm{M}$ phase cell cycle arrest. However, the molecular mechanisms by which altered levels of ADBR2 regulate and orchestrate cellular processes require further investigation to achieve an improved understanding of the role of ADBR2 in cancer cells. Overall, these results provide a possible therapeutic approach for the treatment of human HCC by antagonism of ADBR2.

\section{Acknowledgements}

Not applicable.

\section{Funding}

No funding was received.

\section{Availability of data and materials}

All data generated or analyzed during this study are included in this published article.

\section{Authors' contributions}

DD performed all the experiments, analyzed and interpreted the data, JZ contributed to the cell culture and qPCR. JY design this study, analyzed the data and wrote the manuscript. All authors read and approved the final manuscript.

\section{Ethics approval and consent to publish}

Not applicable. 


\section{Consent for publication}

Not applicable.

\section{Competing interests}

The authors declare that they have no competing interests.

\section{References}

1. Torre LA, Bray F, Siegel RL, Ferlay J, Lortet-Tieulent J and Jemal A: Global cancer statistics, 2012. CA Cancer J Clin 65: 87-108, 2015

2. El-Serag HB: Hepatocellular carcinoma. N Engl J Med 365: $1118-1127,2011$.

3. Artinyan A, Mailey B, Sanchez-Luege N, Khalili J, Sun CL, Bhatia S, Wagman LD, Nissen N, Colquhoun SD and Kim J Race, ethnicity, and socioeconomic status influence the survival of patients with hepatocellular carcinoma in the United States. Cancer 116: 1367-1377, 2010.

4. Antoni MH, Lutgendorf SK, Cole SW, Dhabhar FS, Sephton SE, McDonald PG, Stefanek M and Sood AK: The influence of bio-behavioural factors on tumour biology: Pathways and mechanisms. Nat Rev Cancer 6: 240-248, 2006.

5. Thaker PH, Han LY, Kamat AA, Arevalo JM, Takahashi R, Lu C Jennings NB, Armaiz-Pena G, Bankson JA, Ravoori M, et al: Chronic stress promotes tumor growth and angiogenesis in a mouse model of ovarian carcinoma. Nat Med 12: 939-944, 2006

6. Cherezov V, Rosenbaum DM, Hanson MA, Rasmussen SG Thian FS, Kobilka TS, Choi HJ, Kuhn P, Weis WI, Kobilka BK and Stevens RC: High-resolution crystal structure of an engineered human beta2-adrenergic $\mathrm{G}$ protein-coupled receptor Science 318: 1258-1265, 2007.

7. Hara MR, Kovacs JJ, Whalen EJ, Rajagopal S, Strachan RT, Grant W, Towers AJ, Williams B, Lam CM, Xiao K, et al: A stress response pathway regulates DNA damage through $\beta 2$-adrenoreceptors and $\beta$-arrestin-1. Nature 477: 349-353, 2011.

8. Quốc Lu'o'ng KV and Nguyễn LT: The roles of beta-adrenergic receptors in tumorigenesis and the possible use of beta-adrenergic blockers for cancer treatment: Possible genetic and cell-signaling mechanisms. Cancer Manag Res 4: 431-445, 2012.

9. Cole SW and Sood AK: Molecular pathways: Beta-adrenergic signaling in cancer. Clin Cancer Res 18: 1201-1206, 2012.

10. Barron TI, Connolly RM, Sharp L, Bennett K and Visvanathan K Beta blockers and breast cancer mortality: A population-based study. J Clin Oncol 29: 2635-2644, 2011.

11. Melhem-Bertrandt A, Chavez-Macgregor M, Lei X, Brown EN, Lee RT, Meric-Bernstam F, Sood AK, Conzen SD, Hortobagyi GN and Gonzalez-Angulo AM: Beta-blocker use is associated with improved relapse-free survival in patients with triple-negative breast cancer. J Clin Oncol 29: 2645-2652, 2011.
12. Shan T, Ma Q, Zhang D, Guo K, Liu H, Wang F and Wu E: $\beta 2$-adrenoceptor blocker synergizes with gemcitabine to inhibit the proliferation of pancreatic cancer cells via apoptosis induction. Eur J Pharmacol 665: 1-7, 2011.

13. Livak KJ and Schmittgen TD: Analysis of relative gene expression data using real-time quantitative PCR and the 2(-Delta Delta $\mathrm{C}(\mathrm{T})$ ) method. Methods 25: 402-408, 2001

14. Kassahun WT, Guenl B, Ungemach FR, Jonas S and Abraham G: Expression and functional coupling of liver $\beta 2$-adrenoceptors in the human hepatocellular carcinoma. Pharmacology 89: 313-320, 2012.

15. Katritch V, Cherezov V and Stevens RC: Structure-function of the $\mathrm{G}$ protein-coupled receptor superfamily. Annu Rev Pharmacol Toxicol 53: 531-556, 2013.

16. Pérez-Sayáns M, Somoza-Martin JM, Barros-Angueira F, Diz PG, Gándara Rey JM and García-García A: Beta-adrenergic receptors in cancer: Therapeutic implications. Oncol Res 19: 45-54, 2010.

17. Weddle DL, Tithoff P, Williams M and Schuller HM: Beta-adrenergic growth regulation of human cancer cell lines derived from pancreatic ductal carcinomas. Carcinogenesis 22: 473-479, 2001.

18. Zhang D, Ma QY, Hu HT and Zhang M: $\beta 2$-adrenergic antagonists suppress pancreatic cancer cell invasion by inhibiting CREB, NFкB and AP-1. Cancer Biol Ther 10: 19-29, 2010.

19. Pérez Piñero C, Bruzzone A, Sarappa MG, Castillo LF and Lüthy IA: Involvement of $\alpha 2$ - and $\beta 2$-adrenoceptors on breast cancer cell proliferation and tumour growth regulation. Br J Pharmacol 166: 721-736, 2012.

20. Toll L, Jimenez L, Waleh N, Jozwiak K, Woo AY, Xiao RP, Bernier $M$ and Wainer IW: \{Beta\}2-adrenergic receptor agonists inhibit the proliferation of $1321 \mathrm{~N} 1$ astrocytoma cells. J Pharmacol Exp Ther 336: 524-532, 2011.

21. Zhang D, Ma Q, Wang Z, Zhang M, Guo K, Wang F and Wu E: $\beta 2$-adrenoceptor blockage induces G1/S phase arrest and apoptosis in pancreatic cancer cells via Ras/Akt/NFkB pathway. Mol Cancer 10: 146, 2011.

22. Liao X, Che X, Zhao W, Zhang D, Bi T and Wang G: The $\beta$-adrenoceptor antagonist, propranolol, induces human gastric cancer cell apoptosis and cell cycle arrest via inhibiting nuclear factor $\kappa B$ signaling. Oncol Rep 24: 1669-1676, 2010.

23. Schuller HM: Mechanisms of smoking-related lung and pancreatic adenocarcinoma development. Nat Rev Cancer 2: 455-463, 2002.

() $\Theta$ This work is licensed under a Creative Commons Attribution-NonCommercial-NoDerivatives 4.0 International (CC BY-NC-ND 4.0) License. 